RHS Revista Humanismo

RT y Sociedad

\title{
Diferencia: aproximación crítica al concepto
}

Difference:critical approach to the concept.

Néstor Cortez Ochoa ${ }^{1 \star}$, Antropólogo, Esp, Magíster.

Este artículo es un fragmento extraído de la conferencia "Diferencia, Educación Intercultural y Derechos Humanos en Colombia", presentada en "The 7th International Congress of Qualitative Inquiry" (QI2011) from May 18th to May 21st at the University of Illinois in Urbana-Champaign, USA.

${ }^{1}$ Docente de tiempo completo, Departamento de Ciencias Sociales y Humanas, Universidad de Medellín, Medellín, Colombia.

Aceptado: enero 28 de 2013.

\section{Resumen.}

Según la literatura pedagógica contemporánea la Escuela de hoy se piensa y se repiensa a sí misma. Fenómenos como la globalización, las migraciones y el multiculturalismo han servido de caldo de cultivo para la emergencia de discursos que giran alrededor de la diversidad cultural. Pero, cómo hablar de diversidad cultural sin abordar el concepto de "diferencia", el cual adquiere un papel protagónico en cuanto a la reflexión surgida en torno a la interculturalidad y, por lo tanto, se vuelve pertinente comprenderlo, desglosarlo, interpretarlo y asimilarlo en toda su dimensión.

Palabras clave: diferencia, diversidad cultural, interculturalidad, desigualdad.

Abstract.

According to contemporary educational literature today's school thinks and rethinks itself. Phenomena such as globalization, migration and multiculturalism have provided fertile grounds for the emergence of discourses revolving around cultural diversity. But, we can not talk about cultural diversity without addressing the concept of "difference", which becomes important when we think about interculturalism and, therefore, it is pertinent to understand this concept in order to break it down, to interpret it, and to assimilate it in all its dimensions.

Key words: difference, cultural diversity, inequality, intercultiralism.

Para citar este artículo: Cortez N. Diferencia: aproximación crítica al concepto. Rev Humanismo y Sociedad, 2013; Volumen 1: 59-63.

${ }^{\star}$ Autor para correspondencia: Néstor Cortez Ochoa. Universidad de Medellín. Departamento de Ciencias Sociales y Humanas. Carrera $87 N^{\circ}$ 30 -65. Oficina 12-214. E-mail: nesstorcortez@hotmail.com 


\section{Introducción.}

Aparentemente la primera evidencia en cuanto al concepto diferencia, se refiere a una construcción con características de flexibilidad y altamente adaptable; pero que en últimas, termina por ser un elemento que posibilita.

... justificar la desigualdad en un mundo cuya condición es la diversidad, gracias a la cual prosigue con éxito la evolución (...) La construcción de la diferencia no es más que una nueva forma de presentar las distancias culturales, sociales y políticas que son legitimadas bajo la apariencia de ausencia de jerarquías sociales pero que ocultan un refinado mecanismo de exclusión. (García Castellano \& Granados Martínez, 1999, pág. 17).

Con la cita anterior se pretende generar sospechas y preguntas en torno al origen del concepto mismo, no me refiero al origen en cuanto etimología, sino en un sentido pragmático, es decir, a la diferencia como una construcción intencional seguramente desde Occidente, buscando dejar bien claro, desde su particular etnocentrismo, que la diferencia es para identificar al "otro" pero en cuanto inferior; es evidenciar una suerte de desigualdad jerárquica, pero para exaltar a quien la propone como el que está en la cima y cuyo estado es inalcanzable por el otro.

La desigualdad trae consigo una compleja carga política; es necesario la existencia del otro para "yo" diferenciarme de "él", quien al no ser igual, no está inscrito en una posición plena de derecho. Ello implica, entrar en el terreno de las clasificaciones y en consecuencia es necesario acudir a estrategias que posibiliten aglutinar, agrupar, seleccionar, asimilar, separar, diferenciar y descartar con criterios, que por supuesto son propuestos por quien necesita establecer la diferencia, y en este sentido asumir distancia jerarquizada frente otro.

\section{¿A qué acudir para establecer la diferencia?}

Fundar criterios desde la taxonomía, va más allá de la identificación cromática de los individuos. Una clasificación que contemple exclusivamente estos criterios, sería pobre porque no justifica en sí misma su intención, es decir una sociedad que al auto reconocerse como dominante, se otorgue el derecho del control sobre las demás. En otras palabras, es necesario identificar algo que esté más allá del color de la piel.

No obstante, reconocerse diferente exclusivamente desde las condiciones culturales y sociales, también es una apreciación reduccionista. En las últimas décadas, ha habido grandes avances en el campo de la genética; la relación entre ésta y la socio biología, ha generado una gran controversia; cuando intenta identificar en las bases biológicas algunas conductas sociales. Búsqueda por demás altamente sospechosa y con una marcada tendencia al reduccionismo. Suponer que en los genes está inscrita la dinámica social, es un asunto interesante, pero genera desconfianza, máxime cuando las sociedades supuestamente "inferiores" -según Occidente- deben aceptar su condición de desventaja, gracias al origen genético.

No obstante, por otro lado, la historia está cargada de ejemplos, en los que el racismo se justifica desde aspectos socioculturales. La teoría racista imperial, por ejemplo, coincide en exponer que las razas no constituyen unidades biológicas aislables y que no se podría dividir la naturaleza en razas humanas diferentes. Asimismo, "acepta que el comportamiento de los individuos y sus capacidades o sus aptitudes no son el producto de su sangre ni de sus genes, sino que se deben al hecho de pertenecer a diferentes culturas históricamente determinadas" (Wallerstein, 1988).

Lo que hoy conocemos como Europa se compone de una pluralidad de culturas cuyos orígenes han sido sistemáticamente reinventados frente al bárbaro, al infiel, al salvaje, al pobre, al inculto, etc., en una construcción lineal de la historia, desde Grecia hasta el modo de vida típicamente occidental de finales del siglo $X X$, en la que la mejor parte se la llevan aquellas culturas grupos socialmente dominantes- que han tenido poder $y$ privilegio para definirse y distanciarse de los diferentes (García Castellano \& Granados Martínez, 1999, pág. 26).

En cualquiera de los casos, está inmersa la idea contemporánea de progreso. Idea que resulta del esfuerzo por la construcción de una sociedad civilizada, entendida como aquella que toma distancia de un estado inferior, del salvajismo. Es el progreso un "caballito de batalla", en la medida en que sobre él se desarrolla gran parte del proyecto que Occidente ha llamado modernidad, “....en el siglo XIX, la modernidad es asumida como una oposición absoluta entre lo 
tradicional y lo moderno, y el término progreso está más vinculado a la técnica y la producción de bienes" (Cortez, 2006, pág. 2)

Ahora bien, argüir diferencias desde posturas biológicas o socioculturales, no parece un asunto convincente. Cualquiera que sea el argumento, deja la sensación de vacío. Sin embargo, al establecer una relación dialéctica entre naturaleza y cultura, el asunto puede ser distinto.

Los genes no son garantía, vistos como unidades independientes; la cultura tampoco, asumiéndola como componente separado. No obstante, al intentar analizar la compleja relación entre ese aquello natural que hace parte de las sociedades humanas, entendiendo la "naturaleza" como aquello donde el hombre no ha impuesto un orden cultural, o en palabras de Zygmunt Bauman, donde no hay más que "silencio del ser humano" (Bauman, 2005, pág. 25) y, por otro lado, la cultura como ese complejo e interrelacionado conjunto de hábitos que son compartidos, aprendidos y simbólicos, es posible establecer algunas particulares dándole carácter de identidad a un grupo, posibilitando diferenciarse de otro.

La relación naturaleza - cultura, en palabras de Arturo Escobar, no debe ser asumida como entes dados y presociales, sino como constructos culturales, si es que deseamos determinar su funcionamiento como dispositivos para la construcción cultural, de la sociedad humana, del género y de la economía (MacCormack y Strathern, 1980 citado en Escobar, 2000, pág. 118).

No es posible separar la naturaleza de la cultura, ni la cultura de la naturaleza, puesto que la categoría de humano impone esta doble condición. Hablar de la naturaleza, desde nuestra condición humana cultural, termina siendo un desafío improcedente, puesto que hacemos parte tanto de lo natural, como de lo construido.

Es por lo tanto allí, justo en dicha relación, donde se podría intentar ubicar el concepto de diferencia; pero ello ya lo hace una tarea cuidadosa, dado la alta vulnerabilidad a ser influenciado ideológicamente. Los discursos a favor de la igualdad, pueden alcanzar logros tales como la promulgación de los Derechos del Hombre, pero en la práctica, dicho sentido de igualdad está condicionado a intereses políticamente particulares, que superan el sentido mismo de la propuesta.

Cuando desde Occidente, se decide (atendiendo una necesidad) clasificar el globo terráqueo en categorías que van desde el primero hasta el cuarto mundo, siendo este último, el conformado por los más pobres de los países menos desarrollados, surge la necesidad de atribuirle ciertas características a cada uno de los "mundos". Aspectos como la economía, el desarrollo, el fenotipo, unas supuestas bases biológicas, lengua, ubicación geográfica, condición política ${ }^{1}$ y posición frente al colonialismo, adquieren una connotación especial a la hora de construir procesos de identidad.

El singular resultado de la combinación de estos rasgos, fortalecidos por su propia historia, le da un carácter de identidad colectiva, sobre el cual se teje la diferencia, con respecto a otros grupos. En palabras de Arturo Escobar, se trata de "identificar los discursos socialmente significativos sobre la diferencias (...) y las maneras en que puedan operar como discursos de articulación de alternativas" (Escobar, 2000, pág. 135). Dicho de otra manera, "Muchos antropólogos y estudiosos de las culturas tradicionales coinciden en considerar que "lo propio" de una cultura es el conjunto de sus rasgos diferenciadores en relación al resto" (Heise, Tubino, \& Ardito, 1994, pág. 4).

Pero, como supuestamente aceptamos que la cultura no es estática, todo lo contrario, es sumamente flexible y su conservación también está alimentada por el cambio, donando y recibiendo modos culturales nuevos. La apropiación de lo externo "puede adoptar una diversidad de estilos, llegando a ser asumida vivencialmente por el grupo étnico. $\mathrm{Si}$ dicha apropiación no elimina los valores fundamentales de una cultura, pasa a formar parte de lo propio de esta cultura." (Ibíd. pág. 4). En definitiva y como aporte a la educación intercultural, "se trata de diseñar sistemas de compensación educativa mediante los cuales el «diferente» pueda lograr acceder con cierta rapidez a la competencia en la cultura dominante, siendo la escuela

\footnotetext{
${ }^{1}$ Al segundo mundo por ejemplo, pertenecen los países del Pacto de Varsovia, incluida la antigua Unión Soviética, los países socialistas y los que una vez fueron Europa Oriental y Asia.
} 
la que facilita el «tránsito» de una cultura a la otra." (García Castellano \& Granados Martínez, 1999, pág. $51)$.

"La Interculturalidad sin embargo es un paso más: es la interacción y la convivencia de las varias culturas y de sus portadores como iguales, con iguales derechos e iguales oportunidades" (Abram, 2004, pág. 5)

La academia es por tanto protagonista y de alguna manera determinante, porque es a través del fenómeno educativo que se reproducen lógicas de representaciones en la relación con el otro,

... (la diferencia cultural en relación con los sectores dominantes de la sociedad) de las poblaciones subalternizadas, sobre quienes se ha construido una imagen que los ubica como objetos "exóticos", vestigios del pasado salvaje, reductos de identidad, o sociedades en transición hacia la modernidad. A lo largo de esta historia, la "marcación" de la diferencia ha servido como instrumento de legitimación de diversas formas de dominación sobre sujetos y sociedades, y de subalternización de sus conocimientos." (Rojas \& Castillo, 2007, pág. 14)

Ello hace necesario que desde la escuela, se propongan reflexiones encaminadas a la autocomprensión y "la autocrítica de las propias formas culturales, tanto tradicionales como modernas, con el objeto de mejorar sus propias condiciones de vida y afianzar su propia identidad cultural bajo el reconocimiento y la aceptación de la diversidad cultural". (García Castellano \& Granados Martínez, 1999, pág. 79).

$\mathrm{Al}$ respecto se empieza a evidenciar propuestas en las que se contempla una posición que, sin pretender ser fórmula mágica, sí se identifican esfuerzos concretos encaminados a repensar el papel de la educación desde una postura multicultural: En este sentido, García Castellano y Grandos Martínez sugieren que la educación multicultural debe ser aquella que se desarrolla en la sociedad como un proceso de producción y crítica cultural caracterizado por:

1. Contemplar una diversidad en los contenidos culturales transmitidos (...)

2. Asegurar una diversidad de los métodos de transmisión (...)

3. Fomentar los mayores niveles de conciencia posibles por parte de los alumnos, acerca de la diversidad cultural (...)

4. Preparar a los estudiantes con los recursos congnitivos necesarios para: a) conocer la diversidad y las diferencias culturales existentes en sus entornos; $b$ ) percibir y analizar las desigualdades sociales, que a veces traducen las diversidades anteriores, desigualdades en la distribución del poder y los recursos en la sociedad; c) criticar dicha traducción y construir propuestas de transformación, y d) posicionarse crítica y activamente en la acción social.

5. Desechar la idea de que siempre es irremediable una exclusión mutua entre, por un lado, la preservación de identidades y peculiaridades étnicas o culturales de grupos minoritarios, desfavorecidos y, por otro, la movilidad social ascendente o el acceso a instancias de mayor poder socioeconómico por parte de éstos. (...)

6. Elaborar los programas a partir de una combinación entre el análisis de las comunidades concretas en las que se pondrán en marcha y el compromiso con una concepción global, universal, del hecho cultural. (García Castellano \& Granados Martínez, 1999, págs. 75 - 76)

En esta misma dirección, los autores realizan un recorrido histórico de la educación multicultural evidenciando aciertos y desaciertos. En este orden de ideas establecen cuatro modelos estratégicos diferentes frente a la educación multicultural:

1. Elinicio delos programas en educación multicultural, surge como una respuesta a la educación monocultural, que asumía la educación en una sola dirección como si la cultura fuera una sola, inflexible y congelada.

2. Posteriormente identifican el surgimiento de, lo que en su momento se llamó, la educación compensatoria, que no fue más que un intento por subsanar las desventajas escolares de los niños y niñas en situación de desventaja social y económica.

3. Un tercer momento tiene que ver con una propuesta antirracista, es decir un modelo que buscaba desarticular discursos, prácticas y estructuras que reproducen el racismo.

4. Y finalmente, programas para reconocer la 
discriminación, ya no tanto por cuestiones de raza sino por razón de género, clase social, edad, minusvalías. Op. cit. página 87.

Finalmente, es necesario resaltar que las ciencias sociales han contribuido sustancialmente al debate que gira en torno a la identidad, al nacionalismo, las migraciones, el racismo y las diferentes expresiones de exclusión social. "la sociología, la antropología, la psicología social, la historia, la política, etc., han colmado importantes lagunas de tipo teórico y metodológico y han enriquecido la perspectiva intercultural, en particular la que tiene que ver con la educación" (García Castellano \& Granados Martínez, 1999, pág. 86).

\section{Referencias}

ABRAM, M. L. (16 de febrero de 2004). Estado del arte de la educación bilingüe intercultural en América Latina. Recuperado el 16 de agosto de 2009, de grupobid.org: http:// grupobid.org/sds/doc/IND-MAbramS.pdf

BAUMAN, Z. (2005). Modernidad y ambivalencia. Barcelona: Anthropos.

CORTEZ, N. I. (31 de Mayo de 2006). Explorando la modernidad. Obtenido de Monografias.com: http://www. monografias.com/trabajos33/modernidad/modernidad. shtml?monosearch

ESCOBAR, A. (2000). El lugar de la naturaleza y la naturaleza del lugar: ¿globalización o postdesarrollo? En La colonialidad del saber: eurocentrismo y ciencias sociales (págs. 113 - 144.). Buenos Aires: CLACSO.

GARCÍA CASTELLANO, J., \& Granados Martínez, A. (1999). Lecturas para educación intercultural. Madrid: Trotta.

HEISE, M., Tubino, F., \& Ardito, W. (1994). Interculturalidad, un desafío. Lima: CAAP.

ROJAS, A., \& Castillo, E. (2007). Multiculturalismo y políticas educativas en Colombia ¿Interculturalizar la edcuación? Educación y Pedagogía, 11 - 24.

Wallerstein, I. (1988). Race, nation, classe. París: Éditions de la Découverte. 